\title{
A legal perspective on reproductive health and gender-specific human rights in Nigeria
}

\author{
NI Aniekwu
}

\begin{abstract}
This paper looks at international provisions on reproductive rights and the obligations and duties to protect reproductive health of women in Nigeria. The concept of human rights is very fundamental to society and is based on international instruments signed and ratified by sovereign States after the Second World War. In general, these treaties have established universal standards by recognising fundamental rights and requiring governments to take action to ensure that basic rights are respected. Since the adoption of the Universal Declaration of Human Rights in 1948, efforts have been made by national governments to advocate for human rights, improve the status of women and promote gender equality in every way possible. The centrality of gender-specific human rights in advancing the status of women is now recognised as a sine qua non in attaining the highest standard of sexual and reproductive health. The impact of gender issues on human rights has further led to newer schemes and recommendations on reproductive health as well as advocacies against cultural practices that are harmful to reproductive health.
\end{abstract}

\section{INTRODUCTION}

Reproductive health has been described as the total well being in all matters relating to the reproductive system and it's functions and processes. Reproductive health therefore implies that people are able to have a satisfying and safe sex life and that they have the capability to reproduce and the freedom to decide if, when and how often to do so. Implicit in this last condition is the right of men and women to be informed and to have access to safe, effective, affordable and

KeY WoRDs: Gender, legal perspective, reproductive health

Correspondence: Department of Public Law, Faculty of Law, University of Benin, BeninCity, Nigeria.

(C) CMS UNIBEN JMBR 2004; 3(1): 21-29 acceptable methods of family planning of their choice, as well as other methods of their choice for regulation of fertility, which are not against the law and the right of access to appropriate health care services that will enable women to go safely through pregnancy and childbirth and provide couples with the best chance of having a healthy infant. ${ }^{2}$

In the context of this positive definition, reproductive health would have a number of basic elements. It means that people have the ability to reproduce, to regulate their fertility, and that women are able to go safely through pregnancy and childbirth, and that reproduction is carried to a successful outcome through infant and child survival and well being. ${ }^{3}$

The World Health Organization also defines health as a state of complete physical, 
mental and social well being, not merely the absence of disease or infirmity. ${ }^{4}$ Reproductive health is an important component of health for both men and women, even though reproductive functions are generally gender specific. A major burden of disease in females is related to reproductive functions and the way in which society treats or mistreats women because of their gender. ${ }^{5}$ Thus, reproductive health is not only a major health issue; but also a development and human rights issue, and States must take affirmative measures to ensure that reproductive health care is available and protected.

\section{THE RIGHT TO REPRODUCTIVE HEALTH}

Reproductive rights have been described as gender-specific human rights that are already recognised in national laws and international human rights instruments. These rights rest on the recognition of all individuals to decide freely and responsibly the number, spacing and timing of their children and to have the information and means to do so, and the right to attain the highest standard of sexual and reproductive health. They also include the rights to make decisions concerning reproduction free of discrimination, coercion and violence. ${ }^{3}$

The Convention on the Elimination of All Forms of Discrimination Against Women (CEDAW) also provides that States parties must take appropriate measures to eliminate discrimination against women in the field of health care in order to ensure on the basis of equality of men and women, access to health care services, including those related to family planning. ${ }^{6}$ The committee on CEDAW, the United Nations body that monitors compliance with the women's convention, has addressed governmental obligations pertaining to reproductive health care. In its general recommendation on women and health, it declared that States parties should ensure universal access for all women to a full range of high quality and affordable health care, including sexual and reproductive health services. ${ }^{7}$

In 1994, the United Nations International Conference on Population and Development (ICPD) adopted a Programme of Action and took a broad view of women's sexual and reproductive rights. It specifically noted that reproductive health care should promote sexual health in order to enhance life and personal relations. ${ }^{2}$ In 1995, the Fourth World International Conference on Women in Beijing confirmed the centrality of reproductive rights in advancing the status of women and went further by recognising women's right to control their own sexuality and sexual relations and to decide on these matters on an equal basis with men. ${ }^{3}$

The International Conference on Population and Development set out the context and content of reproductive rights as well as the reproductive health of individuals or couples, and also re-affirmed the rights of women as being central to all aspects of reproductive health. ${ }^{2}$ These aspects of reproductive health include the promotion of safe motherhood, treatment and care for persons living with HIV/AIDS and other STIs, safe abortion, and quality contraception and population control. ${ }^{1}$ The Fourth World Conference on Women in Beijing 1995 reaffirmed and strengthened the 1994 Cairo consensus on women's reproductive health and rights and provided that the right to reproductive health gives rise to a governmental duty to ensure the availability of reproductive health services and remove existing legal barriers to reproductive health care. ${ }^{3}$ As a direct result of these international initiatives, the past few years have seen expanded international, governmental and non-governmental actions to improve women's reproductive health and promote sexual right. ${ }^{8}$

Reproductive rights, also referred to as sexual rights, include the right to be free from 
sexual violence and coercion and the right to the highest standard of sexual health. Sexual health implies a positive approach to human sexuality and includes the freedom from sexual abuse, coercion or harassment, protection from sexually transmitted diseases, and success in achieving or in preventing pregnancy. Defining and exploring reproductive and sexual rights clarifies their location within the framework of empowerment and facilitates the need for a change in gender power relations.

\section{PRINCIPLES OF REPRODUCTIVE RIGHTS}

In 1995, the Beijing Platform of Action noted that reproductive rights embrace certain human rights that are already recognised in national laws, international human rights documents and other consensus documents. ${ }^{3}$ Consistent with its broad view of reproductive health, the ICPD Programme of Action directs States to address gender inequities that impede reproductive health, including discriminatory social practices, negative attitudes towards women and girls, and the limited power many women and girls have over their sexual and reproductive rights. ${ }^{2}$ The Beijing conference produced two documents; the Beijing Declaration and the Beijing Platform for Action. These instruments reaffirmed the principles adopted in Cairo's ICPD Programme of Action and went further to recognise reproductive rights under international law. These rights include: (1) access to population and family planning services; (2) safe legal abortions; (3) prevention and control of HIV/AIDS and other sexually transmitted infections; (4) legal protection from harmful traditional practices affecting reproductive health including female genital mutilation; and (5) criminalisation of domestic violence against women including sexual violence in the private sphere.

In July 1999, the international community gathered again to negotiate a document with important implications for reproductive rights. This meeting was a five-year review of the 1994 ICPD and the Programme of Action. The document adopted is an important affirmation of the principles agreed to in 1994 and also contains crucial strategies for advancing and promoting reproductive rights. ${ }^{9}$ The instrument embraces existing principles contained in declarations of international human rights charters and conferences including the African Charter on Human and People's Right (Banjul 1981), the Nairobi Forward-Looking Strategies for the Advancement of Women (Kenya 1985) and the Vienna World Conference on Human Rights in 1993. These human rights documents refer to reproductive rights as human rights that are exercised by, and imply responsibilities and duties for, men and women.

Reproductive and sexual rights are thus highly interconnected and derivable from political, civil, social and economic rights. They are indivisible and interdependent and share the same foundation on a global level with emerging "solidarity rights" that demand international cooperation to ensure equitable development and peace and ultimately advance the quality and well being of women and all people, in their communities and in everyday life, calling as it does for accountability of all actors and governments even in the private sphere. ${ }^{10}$ Reproductive and sexual rights cannot be enjoyed or enforced in the absence of other basic, economic and social rights such as food, shelter, health social security, livelihood and education, elimination of poverty and renunciation of inequitable and discriminatory development, structural adjustment programmes and environmental degradation. ${ }^{11}$

In addition to the afore-mentioned international instruments, Nigeria also ratified the International Covenant on Civil and Political Rights and the International Covenant on Economic, Social and Cultural Rights. ${ }^{12}$ The constitution of the Federal Republic of Nigeria 
upholds basic civil, political, social and economic rights and protects women against any discrimination based on gender. ${ }^{13}$ The State is therefore obliged to domesticate and implement the provisions of these legal instruments and conventions that protect health, equity and equality.

\section{GENDER ISSUES AND REPRODUCTIVE RIGHTS IN NIGERIA}

The successes gained in the international recognition of gender specific human rights have been accompanied by major challenges in Nigeria. In what ways can women be protected by these declarations in their own lives? The State has the responsibility and obligation to adopt laws and policies reflecting the principles of international agreements that have been ratified. However, the content and meaning of national and international human rights law is not sufficiently detailed in their application to reproductive health matters in national jurisdictions. In Nigeria, CEDAW is yet to become a part of the domestic law even though it was ratified in 1985. The Cairo Programme of Action and the Beijing Platform are nevertheless points of advancement in identifying particular steps that countries have agreed to take to achieve reproductive rights within specified time periods. The Nigerian constitution and ratified human rights treaties establish general obligations that can be applied to reproductive health rights and self-determination. ${ }^{14}$

Laws and policies create the framework through which governments affect the behaviour of people. It is important to bear in mind, however, that the degree to which laws and policies influence people's lives depends on whether these measures are implemented and enforced. In Nigeria, even though reproductive health rights have a powerful moral resonance, they have not been enacted into law by the national or state assemblies. Secondly, laws intended to ensure adequate information and quality of care in reproductive health facilities have little weight where there is no government commitment to training health care workers to respect reproductive rights. Similarly, laws ensuring access to reproductive health care services, such as safe abortion, can only be implemented where there is an investment in facilities that are equipped and authorised to perform these procedures. Nonetheless, formal laws and policies are critical indicators of government's commitment to promoting reproductive rights, and this paper emphasiss the importance of legislative reform and initiatives in realising reproductive health rights.

\section{Contraception and family planning services}

The right to determine freely and responsibly the number and spacing of one's children and to have the information and education necessary to do so was first articulated by the international community at the International Conference on Human Rights in Teheran in 1968. This principle has been re-affirmed in a number of international conferences since then, including the Beijing conference. The Women's Convention, adopted in 1979, gave international obligations to this provision, providing that States shall ensure that men and women have the same rights to decide freely and responsibly the number and spacing of their children. ${ }^{5}$

In Nigeria, the National Policy on Population for Development, Unity, Progress and Self-Reliance, adopted in 1988, seeks to make family planning services easily accessible to all couples and individuals at an affordable cost. ${ }^{15}$ This policy provides that government family planning clinics distribute contraceptives at low cost. However, there is often a shortage of contraceptives at these health centres. In addition, because clinics and hospitals within the public primary health care system are mostly located in urban areas, the availability of modern contraceptives in rural areas is extremely limited. 
Traditional and cultural affiliations also constitute obstacles to the use of contraceptives especially in the rural communities. Multiparity is encouraged in many customary societies, and family planning is generally viewed as the man's prerogative. For the rural women, multiple childbearing signals acceptance into the husband's family and is often a status symbol. Cultural beliefs and financial dependency on the husband often prevent many women who desire to plan their families from doing so.

\section{Safe abortion}

The obligation to respect rights requires State parties to refrain from obstructing action by women in pursuit of their health goals. Barriers to women's access to appropriate health care include laws that criminalise procedures only needed by women and that punish women who undergo those procedures. ${ }^{6}$ At the core of reproductive rights is the principle that a woman has the right to decide whether and when to have a child. ${ }^{16}$ When faced with an unwanted pregnancy, she has the right to choose whether to carry the pregnancy to term or not. Governments are bound to respect this basic human right by ensuring that women can access the full range of quality reproductive health services including safe abortion. In addition, laws and policies that regulate abortion should guarantee safe, accessible and affordable abortion services. ${ }^{17}$ International legal support for a woman's right to safe and legal abortion can be found in numerous international treaties and other instruments. ${ }^{3}$

The health effects of unsafe abortion were addressed at two recent UN conferences, the ICPD of 1994 and the Beijing Conference of 1995. The Programme of Action adopted at the ICPD called upon governments to consider the consequences of unsafe abortion on women's health. ${ }^{2}$ In 1999 the ICPD + 5 conference also affirmed that States train health service providers to ensure that abortions are safe and accessible. ${ }^{18}$ According to the Women's Convention, discrimination against women includes laws that have either the "effect" or "purpose" of preventing a woman from exercising any of her human rights or fundamental freedoms on a basis of equality with men. ${ }^{6}$ Whatever their stated purpose, restrictions on abortion discriminate against women by criminalising a health care procedure that only they need, more so as international law guarantees women the right to the highest attainable standard of physical and mental health. ${ }^{19}$

In Nigeria, the criminal and penal laws prohibit abortion except when done to save the life of the expectant mother. ${ }^{20}$ As a result of the country's restrictive laws, women undergo unsafe abortions at the hands of quacks and unqualified medical personnel and face threats to their physical, social and mental health. Between 10 and $50 \%$ of women who undergo unsafe abortions in Nigeria require post-abortion medical attention due to complications arising from the procedure. ${ }^{21}$ The most common complications due to unsafe abortion are incomplete abortion, infection, hemorrhage and injury to internal organs. Where these complications do not result in death, they may result in life-long health injuries or infertility. For a woman who is not ready to be a mother, having a baby can also cause a severe strain on her mental and emotional health. Removing legal and other barriers to abortion services is necessary to protect women's health and requires action on the part of government, NGOs and international donors.

\section{Prevention and control of HIV/AIDS and other sexually transmitted diseases}

The Beijing Platform recognises that women's social subordination and unequal power relations to men are key determinants in their vulnerability to HIV/AIDS. The World Health Organization has noted that HIV/AIDS and other sexually transmitted diseases, the 
transmission of which is sometimes a consequence of sexual violence, are having devastating effects on women's health, particularly the health of adolescent girls and young women. They often do not have the power to insist on safe and responsible sex practices and have little access to information and services for prevention and treatment. ${ }^{22}$ Women, who represent more than half of all adults newly infected with HIV/AIDS and other sexually transmitted diseases, have shown that social vulnerability and the unequal power relationships between women and men are obstacles to safe sex and efforts to control the spread of sexually transmitted diseases. ${ }^{23}$ The consequences of HIV/AIDS go beyond women's health to their role as mothers and caregivers and their contribution to the economic support of their families. In addition, many women's lack of access to quality reproductive health care may allow STIs to go undetected, leaving these women even more physiologically susceptible to HIV infection.

The issues of HIV/AIDS and other sexually transmitted diseases are central to the rights of women and adolescent girls to sexual health. In Africa, where HIV is transmitted primarily through heterosexual contact, women are being infected at higher rates than men. ${ }^{23}$ Recent studies indicate that the rate of HIV/AIDS is increasing faster among young women than among men in lower income countries including Nigeria. ${ }^{24}$ The impact on women of HIV/AIDS is thus one of the most pressing reproductive health concerns of the time. Because women's subordinate role in developing countries heightens their risk of HIV infection, governments must approach this epidemic with a gender perspective. HIV prevention strategies that are not gendersensitive violate women's human right to nondiscrimination in enjoyment of their rights to health and life. While discrimination against people with HIV/AIDS affects both sexes, women with HIV/AIDS also contend with pervasive gender discrimination, making them doubly marginalized. ${ }^{15}$ The Beijing Platform recognises that women's social subordination and unequal power relations to men are key determinants in their vulnerability to HIV/AIDS. ${ }^{3}$ The Platform notes that women often do not have the power to insist on safe and responsible sex practices and have little access to information and services for prevention and treatment. It is therefore imperative that government acts to minimise the impact of the disease upon women's ability to enjoy all of their civil, political, social, economic and cultural rights. ${ }^{26}$

\section{Elimination of harmful traditional practices including female genital mutilation}

The Beijing Platform for Action further stated that any harmful aspect of certain traditional, customary or modern practices that violates the rights of women should be prohibited and eliminated. ${ }^{3}$ The Women's Convention also enjoins States parties to take all appropriate measures to modify the social and cultural patterns of conduct of men and women with a view to achieving the elimination of prejudices and customary and all other practices that are based on the idea of the inferiority or the superiority of either of the sexes or on stereotyped roles for men and women. ${ }^{6}$ The UN Special Rapporteur on Violence against Women has noted that certain customary practices and some aspects of tradition, such as those related to deeply rooted power inequities of society, often constitute a cause of violence against women and girls. ${ }^{27}$

In Nigeria, harmful customs and traditions severely jeopardise the health, well being, and dignity of women and young girls. Practices that are consistently recognised as harmful traditional practices include female genital cutting (FGC)/female genital mutilation (FGM), very early marriage, nutritional taboos and traditional practices associated with 
childbirth. ${ }^{28}$ In many parts of the country, FGC/FGM is performed on girls between the ages of four and twelve, although it is practiced in some cultures as early as a few days after birth or as late as just prior to marriage or after the first pregnancy. It is estimated that 130 million girls and women worldwide have suffered FGC/FGM, and at least two million girls each year are at risk of undergoing some form of the procedure. ${ }^{29}$ The practice carries a strong message about the subordinate role of women and girls in society and is an attempt to repress the independent sexuality of women by altering their anatomy. When performed on minors and nonconsenting women, FGC/FGM violates a recognised human right protected in international and regional instruments and re-affirmed in international conference documents. ${ }^{30}$

\section{Legal protection from domestic violence including sexual violence in the private sphere}

The term violence against women means any act of gender-based violence that results in or is likely to result in physical sexual or psychological harm or suffering to women, including threats of such acts, coercion or arbitrary deprivation of liberty, whether occurring in public or private life. ${ }^{3}$ Violence against women is one of the most physical consequences of the economic, social, political and cultural inequalities that exist between men and women. It is perpetrated by legal and cultural systems that have historically discriminated against women. The international community has recognised that violence against women constitutes a violation of their human rights and fundamental freedoms. ${ }^{1}$ Sexual violence such as rape and forced sex in marriage is a violation of women's reproductive rights since it impacts their sexual and reproductive health and autonomy. It violates women's reproductive rights, particularly their rights to bodily integrity, sexuality and reproductive capacity. Sexual violence severely compromises a woman's right to health including her physical, psychological, reproductive and sexual health.

The international community specifically recognises women's rights to be free from gender-based violence including rape and other sexual violence in the private sphere. CEDAW noted that gender-based violence is a form of discrimination that seriously inhibits women's ability to enjoy rights and freedoms on a basis of equality with men because sexual violence in its various forms maintains women in subordinate genderbased roles and discriminates against them on the basis of sex. ${ }^{31}$ In Nigeria, the criminal law fails to protect women against sexual violence in private and family life and this serves to perpetuate a culture of violence against women. Forced sexual relations within marriage are accepted and tolerated and husbands are not criminally liable for sexual violence at home. ${ }^{32}$ Rape and domestic violence are bound by the culture of silence and cases of sexual violence are often not reported.

\section{CONCLUSION}

Since the adoption of the ICPD Programme of Action in 1994, and the Beijing Platform for Action in 1995, the policies and implementation strategies of many signatory States have reflected the broad view of reproductive health and rights articulated in Cairo. In Nigeria, there are still key challenges in the realisation of reproductive health rights. As mentioned earlier, legislative action and reform can fundamentally change women's status. In addition, concerted efforts at awareness and education, by gendersensitive groups, government departments, international networks, policymakers and even religious leaders will contribute to the desired impact for change. In order to bring about such change, multiple approaches 
should be adopted as part of a long-term strategy for achieving equity and health rights for women.

While the Beijing conference was undoubtedly a catalyst for change, it is mainly through advocacy and the efforts of women's rights activists that the Beijing principles are being translated into solid legislative and policy reforms in different countries. Through policy analysis, legislative drafting, organising, lobbying and litigation, women around the world are seeing gains in the content of the laws and policies that govern their lives.

There is still much to be accomplished in Nigeria to fulfill the commitments made at Beijing and other international conferences. While women's rights advocacy will be at the forefront of strategies for change, government must be mindful of the obligations undertaken by adopting the Beijing Platform for Action in 1995. The adoption of municipal laws and national policies on reproductive health and rights need to be accompanied by genuine efforts to enforce and implement these provisions. Once in place, enforcement of these policies need to be strictly monitored to ensure that reproductive rights are protected and health services delivered in a comprehensive manner, free from coercion, discrimination and violence.

\section{References}

1. CRLP. Reproductive Rights 2000; Moving Forward. New York: The Center for Reproductive Law and Policy, 2000.

2. United Nations. ICPD Programme of Action. Report of the International Conference on Population and Development, Cairo, Egypt, 5-13 September 1994, UN Doc. A/CONF.171/ 13/Rev.1, UN Sales No. 95, XIII, I8, 1995.

3. United Nations. Beijing Declaration and Platform for Action. Fourth World Conference on Women, Beijing, China, 415 Sept.1995, para 95. UN. Doc. DPI/17/ 1766/Wom (1996).
4. World Health Organization. Constitutional definition of health 1988. <http:www.who.org/about-who/en/ definition.html>.

5. Aniekwu Nkoli I. HIV/AIDS and human rights in Nigeria: a perspective on international guidelines. J Med Biomed Res 2003; 2(1).

6. United Nations. Convention on the Elimination of All Forms of Discrimination against Women. Dec.18, 1979, 12(1), 1249 U.N.T.S .13, 19 I.L.M. 33.

7. Committee on the Elimination of Discrimination against Women. General Recommendation No 24 on Women and Health, para. 29, Feb. 2, 1999.

8. Aniekwu Nkoli I. Gender and human rights dimensions of HIV/AIDS in Nigeria. Afr $J$ Reprod Health 2002; 6(3).

9. Center for Reproductive Law and Policy. ICPD + 5:gains for women despite opposition, 1999.

10. ICPD. Sexual and reproductive rights and health as human rights: concepts and strategies: an introduction for activists. NGO Forum, International Conference on Population and Development. Cairo, Egypt, September 1994.

11. Aniekwu NI. Examining the reproductive health and rights of Nigerian women - a legal perspective. Univ Benin Law J 2001.

12. United Nations. International Covenant on Civil and Political Rights. Adopted by the United Nations Assembly, 16th December 1996.

13. Federal Republic of Nigeria. Section 39, Chapters II and IV on Fundamental Objectives, Rights and Directive Principles of State Policy. Constitution of the Federal Republic of Nigeria 1999.

14. Cook RJ and Fathalla MF. Advancing reproductive rights beyond Cairo and Beijing. Int Fam Plann Persp 1997; 22: 115121.

15. CRLP and Women's Centre for Peace and Development. Women's Reproductive Rights In Nigeria: A Shadow Report 3, 1998.

16. United Nations. General Recommendation 21: Equality in Marriage and Family 
Relations, United Nations, Compilation of General Comments and General Recommendations Adopted by Human Rights Treaty Bodies. HRI/Gen/1/Rev.2, 29 March 1996 at 124.

17. Aniekwu NI. Criminal laws and legislative policies relating to abortion and reproductive rights in Nigeria. Ann Med Biomed Res (In press).

18. United Nations. Key Actions for the further implementation of the Programme of Action of the International Conference on Population and Development, report of the Ad Hoc Committee of the Whole of the 21st Special Session of the General Assembly, New York, July 1, 1999. UN Doc./A/S-21/5/ Add.1.

19. UNTS. International Covenant on Economic, Social and Cultural Rights. Dec. 16, 1996.

20. Federal Republic of Nigeria. Criminal Code, Laws of the Federation of Nigeria, CAP 77 Section 230 (1) 1990.

21. Safe Motherhood Inter-Agency Group. Unsafe abortion. http://safemotherhood.org/ init facts.htm.

22. World Health Organization. Sexual and Reproductive Health Research Priorities for WHO for the Period 1998-2003. PCC (10)/ 1997/9, 30 May 1997 at 4-5.

23. UNAIDS. Epidemic Update. 1999; 5(16).

24. Senderowitz Judith. Adolescent Health: Reassessing the Passage to Adulthood. World Bank Discussion Papers 20, 1995.
25. Gruskin Sofia. The impact of reproductive subordination on women's health: negotiating the relationship of HIV/AIDS to reproductive health and reproductive rights. 44 AM. UL Rev. 1191, 1196 (1995).

26. United Nations. Report of the International Conference on Population and Development. New York: United Nations NYA/Conf. 171/ 13. 1994.

27. Coomarasswamy Radhika. Report of the Special Rapporteur on Violence against Women, its Causes and Consequences, submitted to the Commission on Human Rights, UN Doc. E/CN.4/1996/53, Feb. 6, 1996, para. 100.

28. Halima Embarek Warzazi. Third Report of the Special Rapporteur on Traditional Practices affecting the Health of Women and the Girl Child, para. 20, submitted to the subCommission on the Prevention of Discrimination and Protection of Minorities. E/CN.4/sub.2/1999/14, July 9, 1999.

29. Anika R and Nahid T. Female Genital Mutilation: A Guide to Laws and Policies Worldwide. UK: Zed Books, 2000.

30. Commonwealth Medical Association. Nordic J Int Law.

31. CEDAW. General Recommendation No.19 on Violence Against Women, 11th Sess., para.1, U.N. Doc.C/1992/L.1/Add.15 (1992).

32. CRLP and International Federation of Women Lawyers. Women of the world: laws and policies affecting their reproductive lives. Anglophone Afr 1997; 117. 